\title{
Effects of excipients on the structure and dynamics of filgrastim monitored by thermal unfolding studies by CD and NMR spectroscopy
}

Houman Ghasriani, Grant E. Frahm, Michael J. W. Johnston and Yves Aubin*

Centre for Biologics Evaluation, Biologics and Radiopharmaceutical Drugs Directorate, Heath Canada, Ottawa, ON, Canada K1A 0K9

* To whom correspondence should be addressed: Yves Aubin, 251 Sir Frederick Banting

Driveway, Tunney’s Pasture, A/L 2201E, Ottawa, ON, Canada, K1A 0K9, Phone 613-791-1500,

FAX 613-941-8933, E-mail: yves.aubin@canada.ca 


\section{Supporting Information}

Figure S1: Effects of polysorbate- 80 on A) $\left.\mathrm{T}_{1}, \mathrm{~B}\right) \mathrm{T}_{2}$, and C) heteronuclear NOE on Met-GCSF at $600 \mathrm{MHz}$.
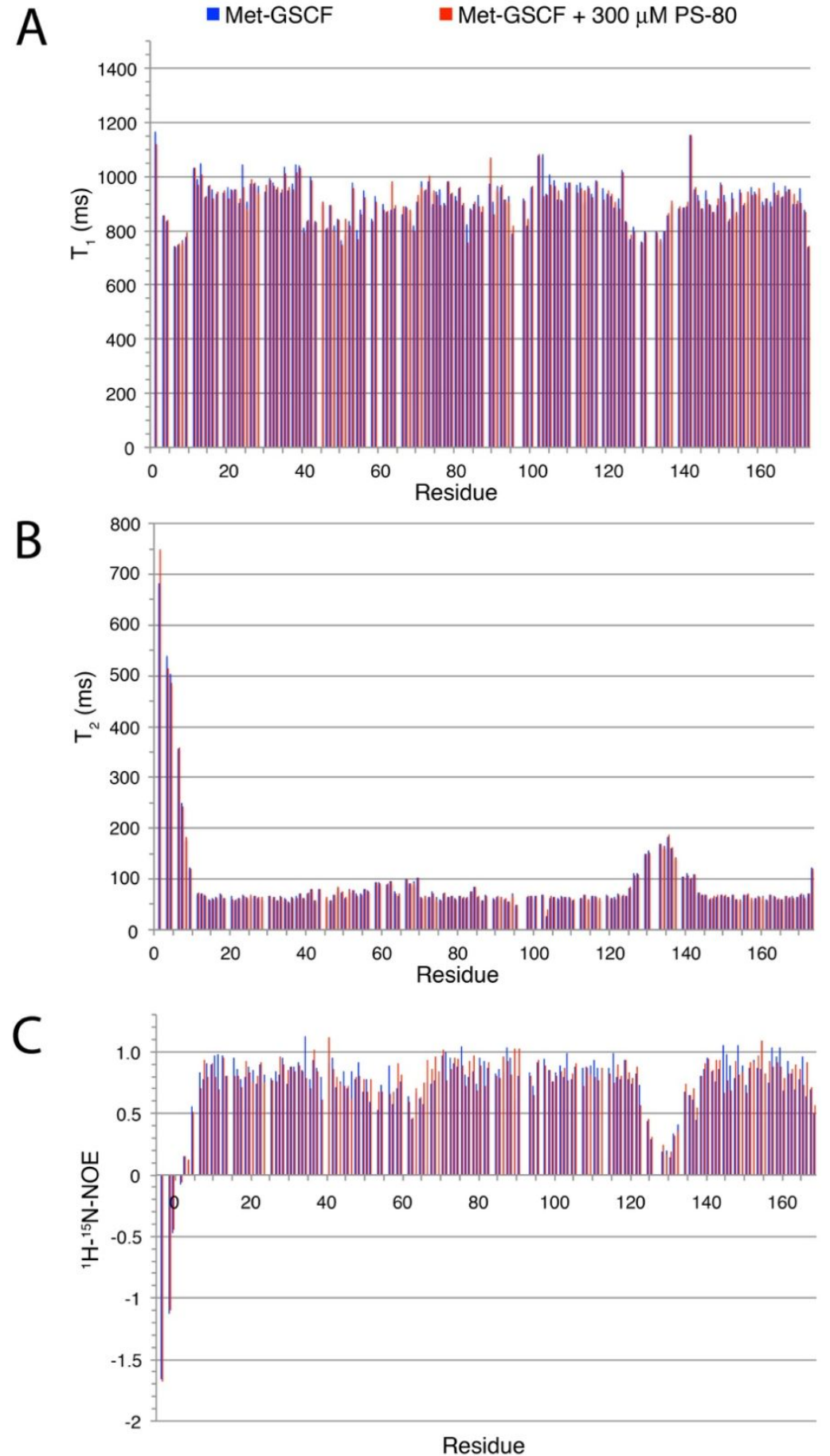
Figure S2: Effects of polysorbate-20 on A) $\mathrm{T}_{1}$ and B) $\mathrm{T}_{2}$ at $600 \mathrm{MHz}$.
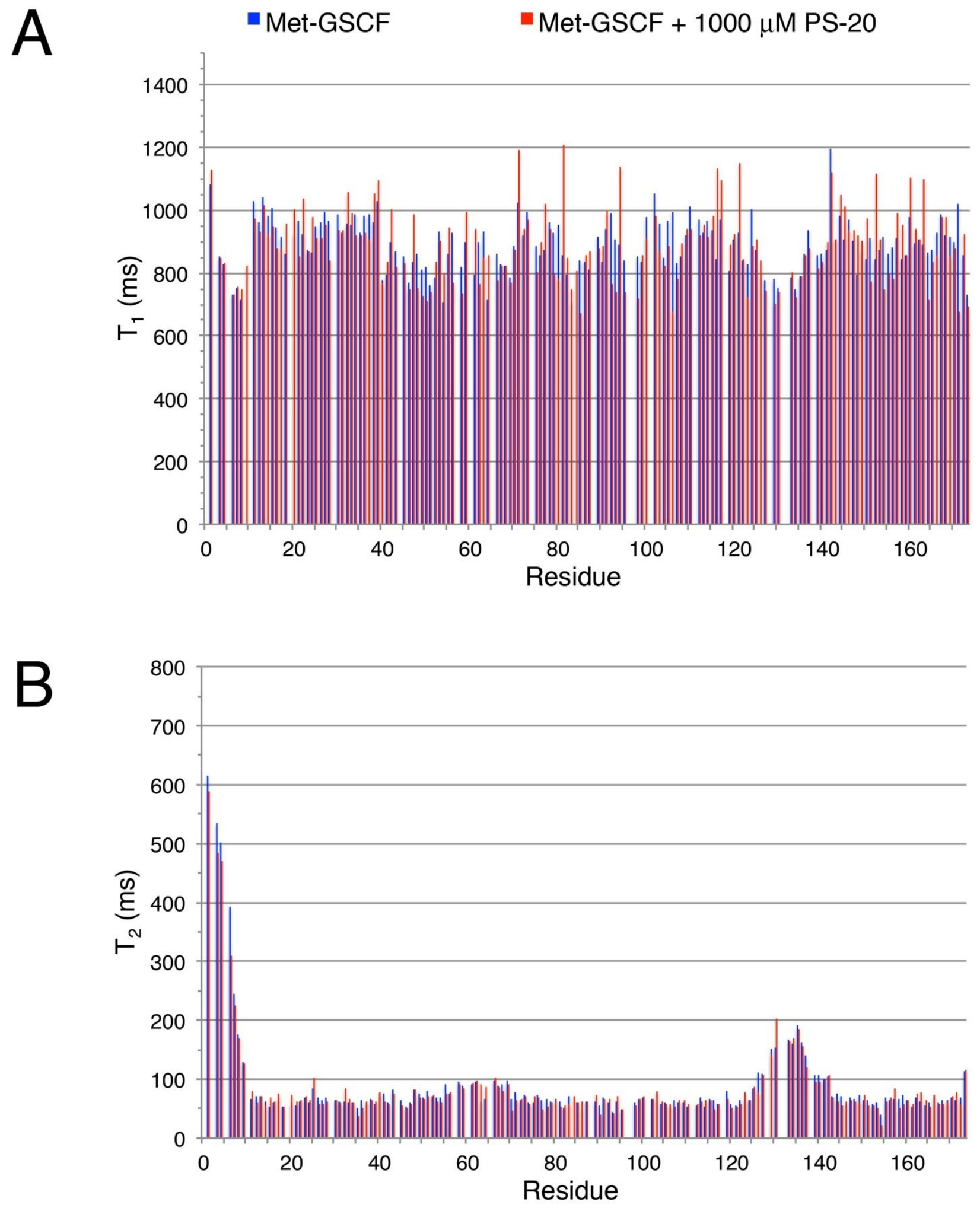
Figure S3: Effects of $\mathrm{pH} 4.0$ and 6.0 on A) $\left.\mathrm{T}_{1}, \mathrm{~B}\right) \mathrm{T}_{2}$ C) heteronuclear NOE on Met-GCSF at 600 MHz. D) order parameters at $\mathrm{pH} 4.0$ and 6.0. Data for $\mathrm{pH} 5.0$ were omitted for sake of clarity.

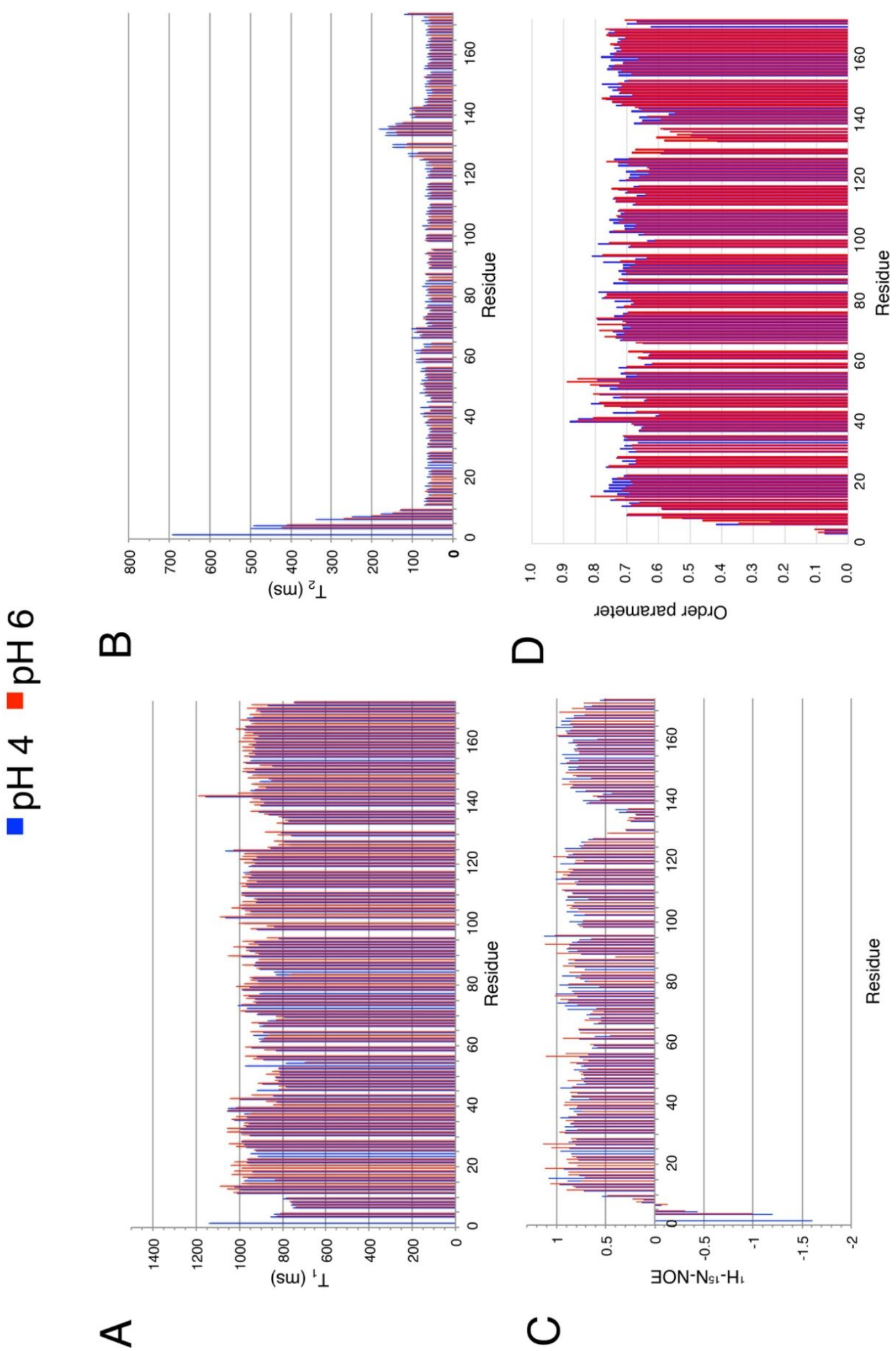


Figure S4: Effects of sorbitol at 0 and $793 \mathrm{mM}$ on A) $\left.\mathrm{T}_{1}, \mathrm{~B}\right) \mathrm{T}_{2}$ and C) heteronuclear NOE on Met-GCSF at $600 \mathrm{MHz}$.

A

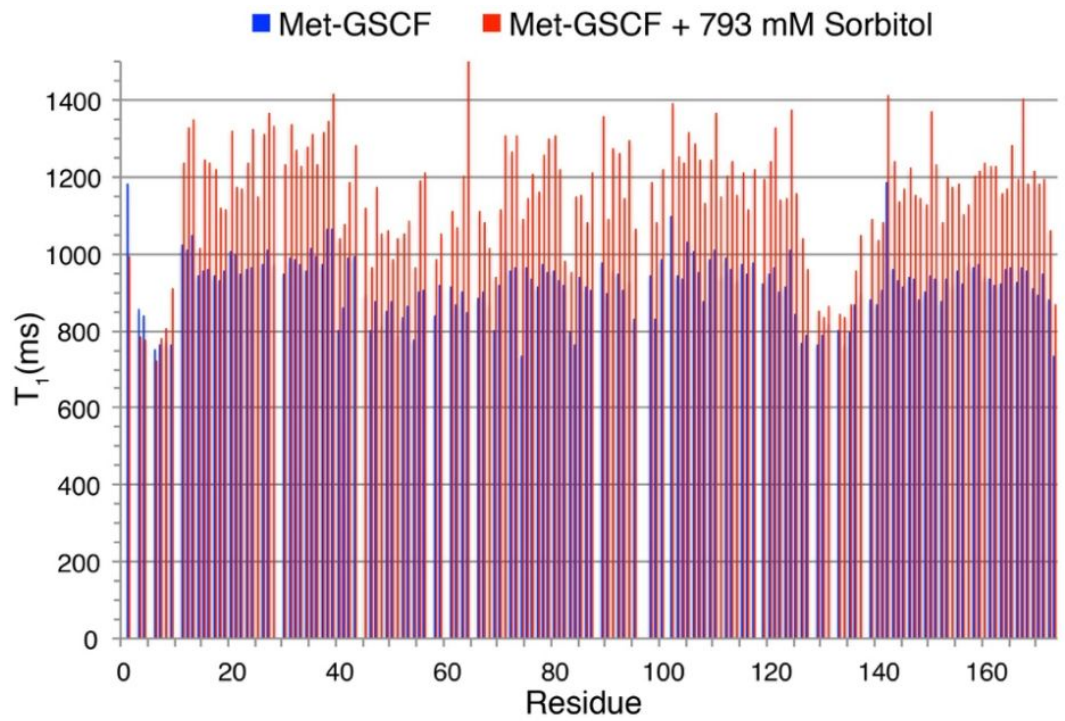

B

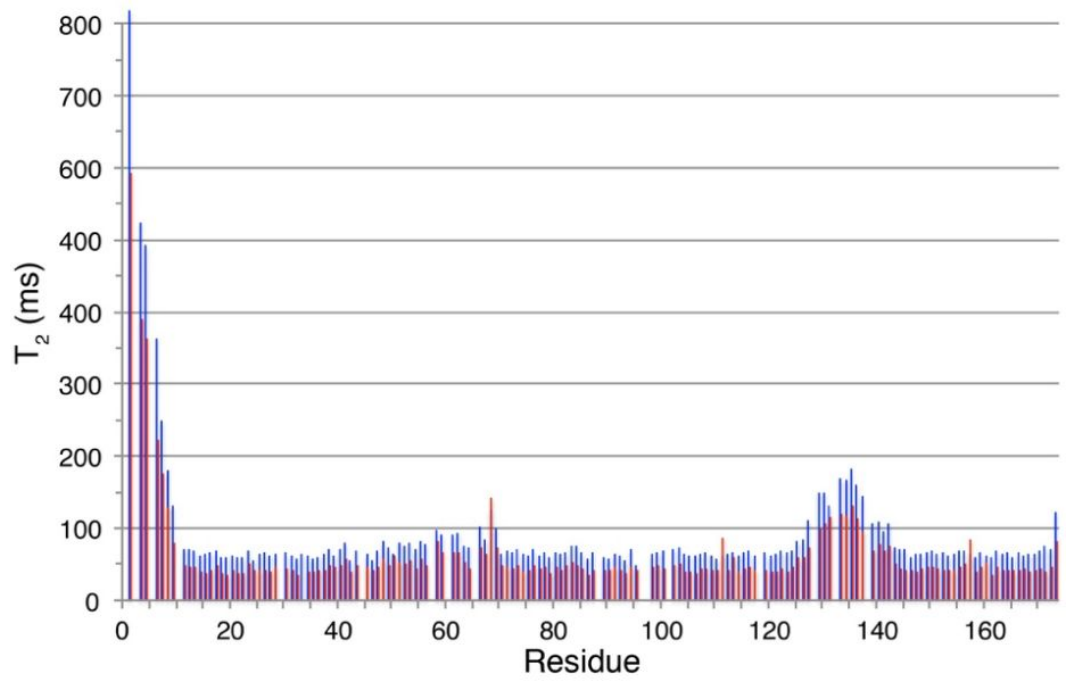

C

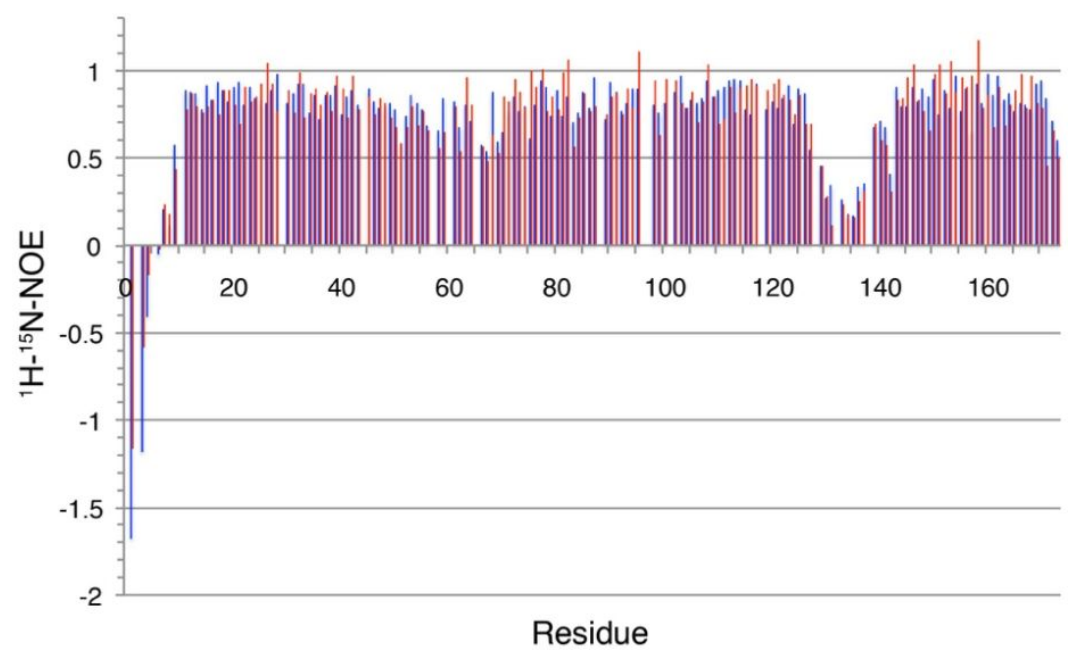


Figure S5: A) Order parameters calculated for Met-GCSF at $0 \mathrm{mM}$ (blue) and $793 \mathrm{mM}$ (red) sorbitol. B) Optimised diffusion tensor for Met-GCSF free (blue) and with $793 \mathrm{mM}$ sorbitol (red) that allowed conversion of the calculation of order parameters.

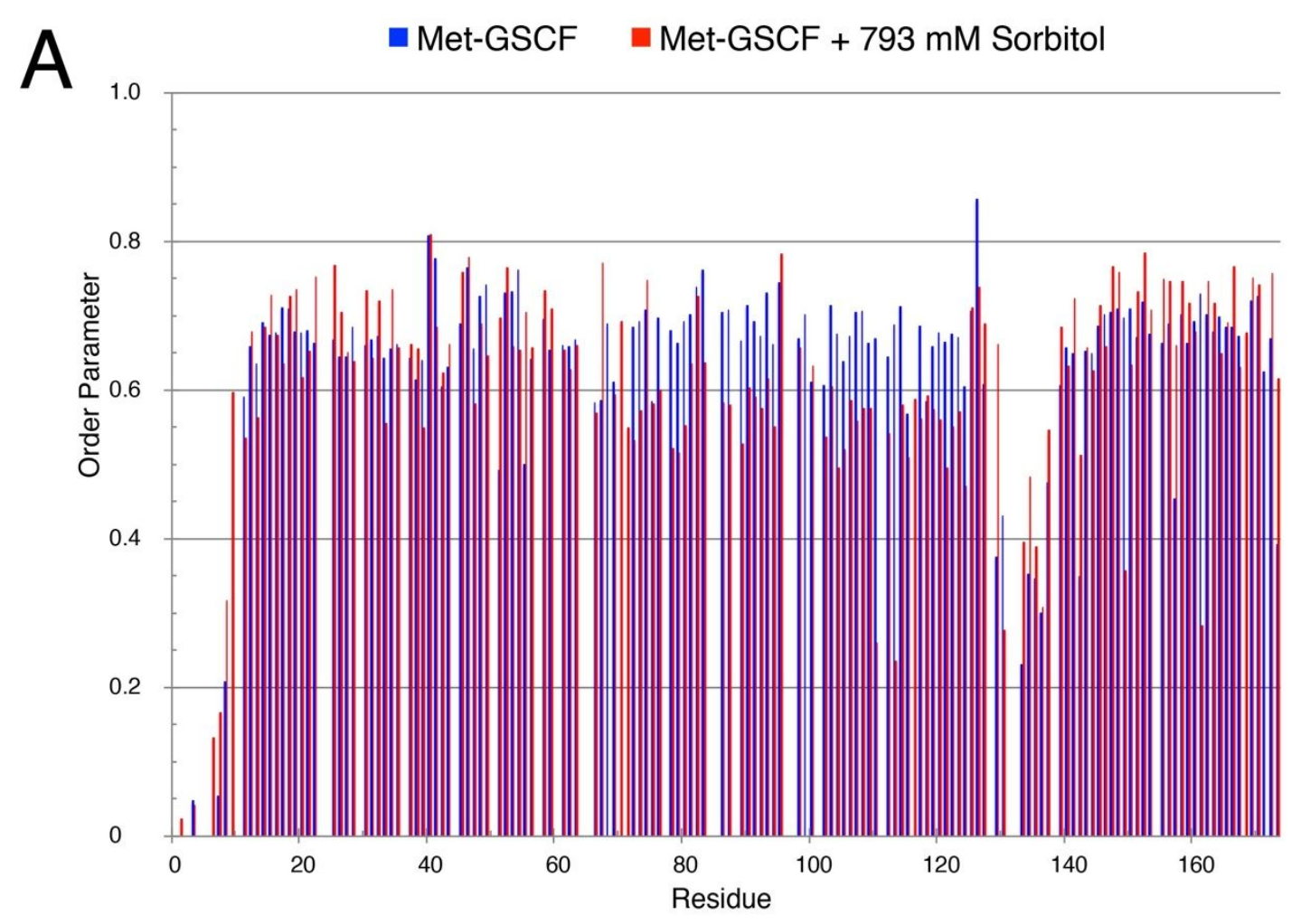

B
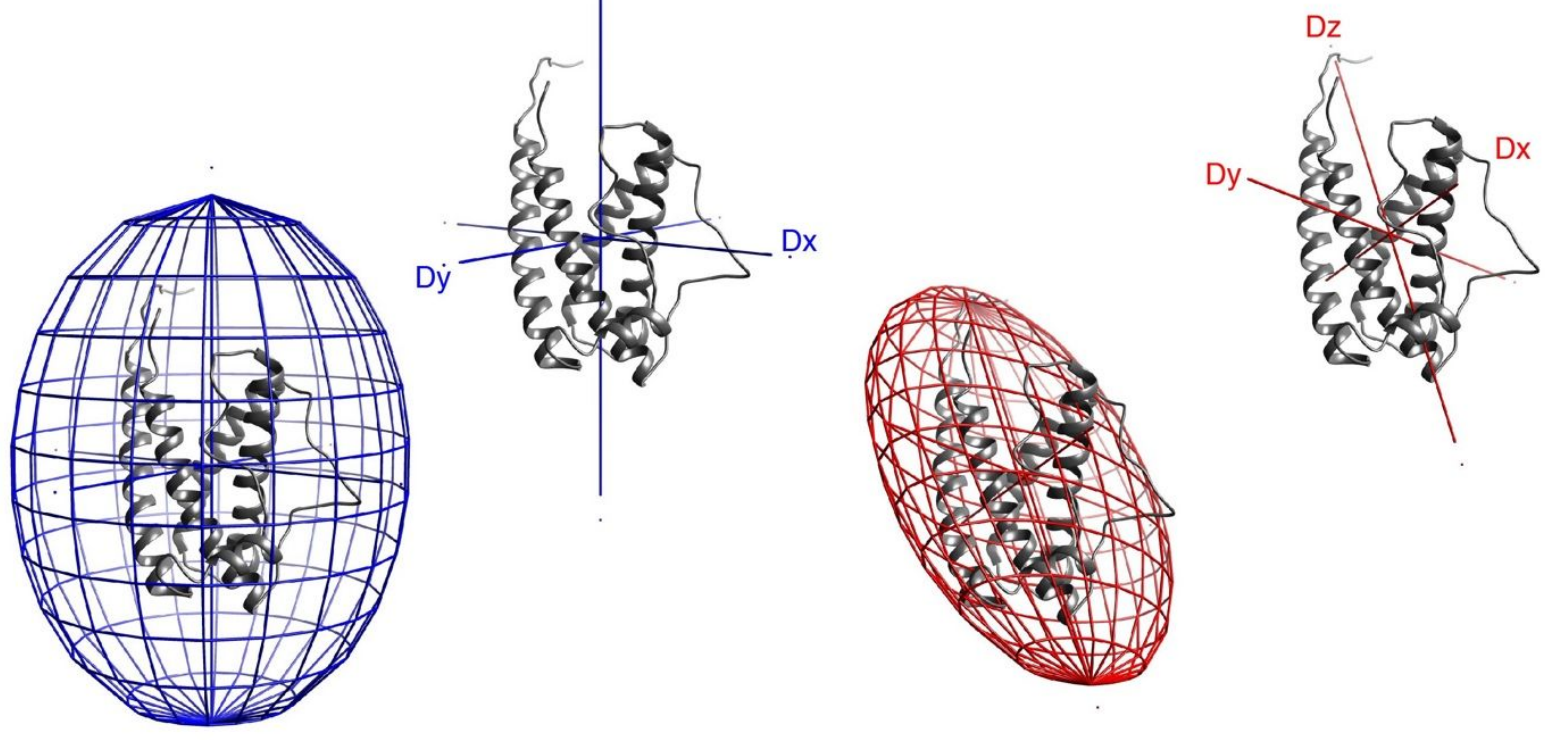